This item was submitted to Loughborough's Research Repository by the author.

Items in Figshare are protected by copyright, with all rights reserved, unless otherwise indicated.

\title{
Environmental impact of mining
}

PLEASE CITE THE PUBLISHED VERSION

PUBLISHER

(c) WEDC, Loughborough University

VERSION

VoR (Version of Record)

PUBLISHER STATEMENT

This work is made available according to the conditions of the Creative Commons Attribution-NonCommercialNoDerivatives 4.0 International (CC BY-NC-ND 4.0) licence. Full details of this licence are available at: https://creativecommons.org/licenses/by-nc-nd/4.0/

\section{LICENCE}

CC BY-NC-ND 4.0

\section{REPOSITORY RECORD}

Elson, Bob, and Margaret E. Ince. 2019. "Environmental Impact of Mining”. figshare. https://hdl.handle.net/2134/28627. 


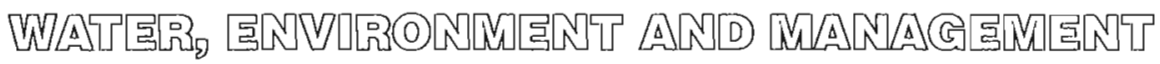

\section{Environmental impact of mining}

\author{
Bob Elson and Margaret Ince
}

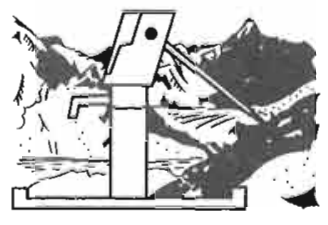

\section{INTRODUCTION}

In today's economic climate all countries need to exploit whatever natural resources they have, including mineralogical ones. To do this the various rocks and minerals are mined either by opencast/openpit methods or by underground mines.

The economies of extractive industries are well documented but what also needs to be considered is the effect these operations have on the environment, whether they are acceptable or how positive effects can be enhanced and negative impacts minimised. To facilitate this an objective assessment system is required. An environmental assessment is one way to achieve this.

Using Opencast Coal Mining in Great Britain as an example, the effects of the operations will be discussed, in terms of the social and physical environment and also some of the problems of making an objective Environmental Impact Assessment will be highlighted.

When considering possible effects and consequences, several stages are required.

1. Understand all aspects of the mining operations.

2. Identify all consequential effects, their magnitudes and importance.

3. Establish an impartial objective scoring system.

4. Draw conclusions from the study.

At each stage ecological, physiochemical and socioeconomic data specific to the actual site(s) of the proposed mining operation will be evaluated.

\section{MINING SYSTEM}

To make a meaningful assessment the first requirement is to fully understand the system creating the disruption. Opencast coal mining is a relatively simple system used for the extraction of shallow coal seams to a maximum depth of 250 metres. Figure 1 illustrates a typical opencast site.

A large hole is dug in the ground and the overburden (noncoal rock) is removed to expose the coal seams. The coal is then removed selectively to ensure an uncontaminated product. The economies of the operation and maximum depth of excavation depend on the ratio of coal to overburden and the complexity of the geological structure. .

All operations are mechanised with some of the equipment being very large. Bulldozers, motorscrapers, draglines and face shovels are all used to excavate and the rock is transported by dump trucks, lorries, conveyor belts and railway wagons. The size of the equipment being dictated by the planned output levels, the duration of the working, the areal extend and the total depth to be mined.

Mining takes place in a progressive manner with overburden dug from one area being used to infill a previously excavated area. In Britain all opencast sites have to be fully restored either to agriculture or for future building development.

It must be stressed that the system should be fully understood so that subtle effects with far reaching consequences are not missed. An example of this is that there will be large areas of bare rock with no vegetation. Rapid runoff of precipitation will occur and the site will have large volumes of suspended solids. The exposed rock will also weather and oxidise and this will make the runoff water acid again capable of polluting water courses away from the site.

\section{EFFECTS OF MINING}

When the mining system is understood the next stage is to identify the consequential effects or impacts on the social and physical environment. These effects can be both negative and positive, short term and long term.

\section{Negative}

Visual - Perhaps the mosi subjective impact but large excavations are usually considered to detract from a landscape. However, opencast mining can be utilised to restore land derelict from eariy industrialisation.

Disruption of the ecosystem - Habitats are destroyed, vegetation destroyed and animals dispossed, during the lifetime of the mine. However, they may return to their natural balance once operation is ceased and land restored. 


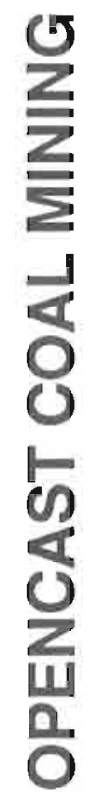

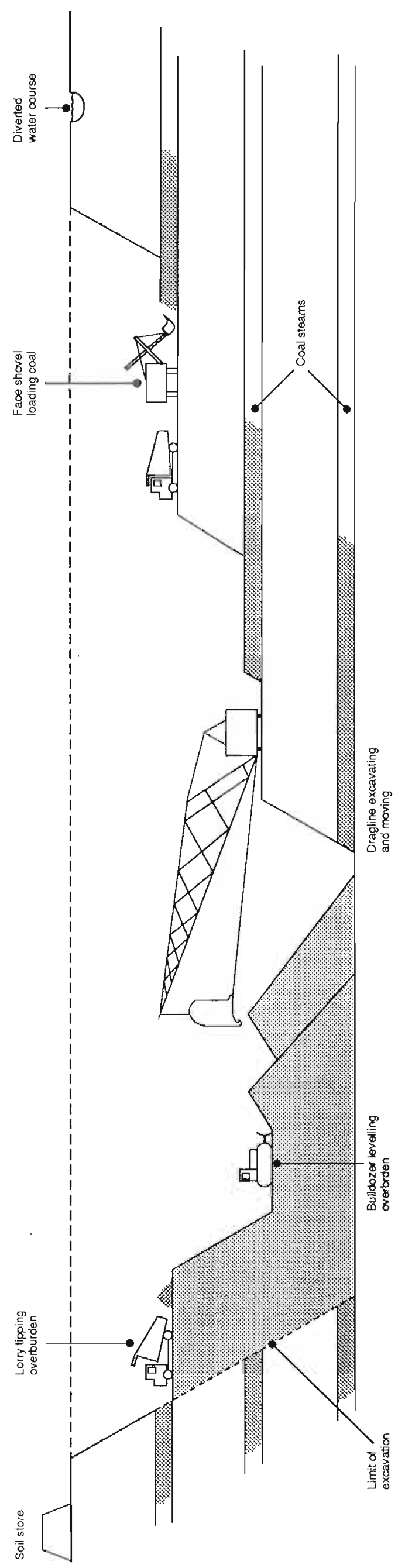

금 
Land is lost to agriculture - Perhaps only for a few years but even after proper restoration it takes a long time to achieve its former fertility. It will also take many tens of years for the area to regain a semblance of a natural landscape.

Drainage - Rivers and streams may need to be diverted and the new courses iend to be straight and hostile to life. Runoff will be rapid and there is greater risk of pollution from suspended solids or acid water. On restoration a totally new drainage system will need to be created.

Groundwater - If aquifers are intersected by the excavation, pumping will be required over a long period and this can lower the water table over a large area. The lack of vegetation cover and exposed rock increases the vulnerability of groundwater to pollution.

Dust - Excavating and transporting broken rock creates dust which can be carried by the wind over a large area. As well as being socially unacceptable rock dust can be injurous to both plants and animals.

Transport - Whether by road or rail the transport of material will have negative impacts on flora and fauna. It may also pose a health impact on local human populations. These effects are usually greater for transport by road when damage to highways is also incurred

Gas - When coal bearing strata are exposed, methane is given off - this is a 'greenhouse gas'. Carbon dioxide is also given off when coal is exposed, by slow oxidation, but the quantity is insignificant compared to that emitted by the internal combustion engineers of the mining machinery.

Noise - Layers of hard rock may require blasting and unless carried out carefully, noise and vibration can be disruptive to nearby properties and inhabitants. Large numbers of site vehicles can significantly increase the ambient noise levels especially if safety warning sirens are in use. If transport of mined material is by road this will prolong the noise impacts.

Land Stability - Improper site design can allow instability of sidewalls and affect adjacent land or property. Restored and infilled excavations will continue settling for several years, making them unsuitable for development unless special restorative techniques are utilised.

Land value - Because of the degradation of the land and destruction of habitats, the land value will rarely be maintained after restoration works. This can reflect on the value of property in the district.

Loss of Resource - Once coal is extracted the community resource base is depleted.

\section{Positive}

Value of Coal - Usually the major factor justifying the environmental disruption is the economic value of the fuel to the community. There is also the benefit of using opencast rather than deep mining methods, which are more costly on resources.
Social/Cultural - These are very specific to the area. They witl depend on a number of factors including the history of mining and other employment in the area; the balance of local population with in-migrants; the development of secondary and service industries etc. Detailed discussion of these aspects are outside the scope of this paper.

Employment - Jobs are created by industry and this has a positive affect on community development. Jobs in secondary and service industries may have marked positive long term effects.

Alternative uses - Opencast mining excavations can be used for the disposal of solid domestic refuse. During final restoration works leisure amenity areas can be created.

\section{SCORING SYSTEM}

Once the environmental impacts are listed, in order to use the data, an assessment needs to be made of the magnitude of the effect and its relative importance. A preferred simple method to achieve this is to create a scoring system which attempts to take an impartial and objective view. This is very difficult as the people involved and affected by major developments tend to have polarised viewpoints and let emotive reactions cloud objective thinking.

A suggested system is to give each impact a numerical value between -10 and +10 , depending on its magnitude and whether it is beneficial or not. A weighting factor between 1 and 10 is also required to reflect the relative importance. The choice of the weighting factor is perhaps the most difficult part and open to much discussion as it must consider ecological importance and social fctors such as community development, economics and politics. An assessment of the state of the environment before development is essential for accurate assignment of the scoring and weighting factors. This necessitates a multidisciplinary team to cover all the requisite skills.

Scores should be given for both during and after the mining and these numbers added before being multiplied by the weighting factor to produce an Impact Score (IS).

$I S=($ during score + after score $) \times$ weighting.

An example for a medium sized opencast site is given in Table 1. 


\section{Table 1}

\section{Environmental Impact Scouring System}

Medium sized opencast coal mine situated in a flat rural area. 2 villages within 1 mile to the south-east and south-west. 1 village 2 miles north. Minor streams affected and no major aquifers intersected.

$\begin{array}{lcccr}\text { Impacts } & \text { during mining } & \text { after mining } & \text { weighting } & \text { IS } \\ \text { Visual } & -4 & -2 & 5 & -30 \\ \text { Ecosystem } & -6 & -2 & 2 & -16 \\ \text { Land loss } & -4 & -1 & 4 & -20 \\ \text { Drainage } & -6 & -2 & 3 & -24 \\ \text { Groundwater } & -2 & -1 & 2 & -6 \\ \text { Dust } & -6 & 0 & 6 & -36 \\ \text { Gas } & -1 & 0 & 2 & -2 \\ \text { Noise } & -4 & 0 & 4 & -16 \\ \text { Stability } & -2 & -2 & 1 & -4 \\ \text { Land value } & 0 & -3 & 4 & -12 \\ \text { Loss of resource } & 0 & -5 & 1 & -5 \\ \text { Value of coal and method } & 10 & 2 & 10 & +120 \\ \text { Employment } & 6 & 1 & 8 & +56 \\ \text { Total } & & & & +5\end{array}$

\section{DRAWING CONCLUSIONS}

In the example the total score is positive which indicates the mining is acceptable but if the result is negative the scores can be used to highlight areas where improvements in the mining system are required if the coal working is to take place.

It should be remembered that the simple scoring system is not adequate on its own but is an aid to objectivity and to restrain the influence of emotive issues. It is often useful in selection of one site from a number of possible sites so that a full environmental assessment is carried out only on the probable site. A more complex analysis can be achieved using a matrix which is linked to the project framework. Using this method, specific activities during site preparation, construction, implementation (site restoration etc) phases are scored against the potential environmental impacts. Positive, negative, short term and long term impacts can be considered. This more detailed assessment places a higher demand on human and finan. cial resources.

\section{SUMMARY}

The object of Environmental Impact Assessment is not to stop development, except in exceptional circumstances, but to ensure the works are done with a full knowledge of possible consequences. This data can then be used to minimise effects during and after the opertions and prevent legacies which will disfigure, blight or poison the environment for future generations.

\section{REFERENCES}

Coal and the Environment. Commission on Energy and the Environment, HMSO, London. 